\title{
The Influence of Learning by Doing Effect and the Accumulation of Human Capital on Economic Growth
}

\author{
Chia-Yang Ning1, Hsien-Yu Shun² \\ ${ }^{1}$ Department of International Trade, Guangdong University of Petrochemical Technology, Maoming, China \\ ${ }^{2}$ Department of Marketing, Guangdong University of Petrochemical Technology, Maoming, China \\ Email: 1702977329@qq.com, jerryhysun@hotmail.com
}

How to cite this paper: Ning, C.-Y., \& Shun, H.-Y. (2021). The Influence of Learning by Doing Effect and the Accumulation of Human Capital on Economic Growth. Open Journal of Social Sciences, 9, 465-471. https://doi.org/10.4236/jss.2021.910033

Received: October 13, 2021 Accepted: October 26, 2021 Published: October 29, 2021

\begin{abstract}
Based on Lucas (1988) human capital model, our paper introduces Romer (1986) the concept of learning by doing and tries to establish an endogenous growth model under a closed economic system, so as to explore the impact on the long-term economic growth rate under the consideration of learning by doing effect and human capital accumulation. We found that when the consumption intertemporal elasticity of substitution is equal to 1 , the growth rate of human capital will show a fixed growth; when the consumption intertemporal elasticity of substitution isn't equal to 1, we have a higher growth rate of human capital. In terms of economic growth rate, regardless of the value of consumption intertemporal elasticity of substitution, we can get a higher economic growth rate. It shows that learning by doing and human capital has a positive effect on the economic growth rate. Even if the human capital growth rate shows a fixed growth, the learning by doing effect can also promote the long-term economic growth rate of the system.
\end{abstract}

\section{Keywords}

Learning by Doing, Human Capital, Economic Growth

\section{Introduction}

Since the middle and late 1980s, endogenous economic growth theory has become an important research topic in the macroeconomic field. Many economists began to look for the engine of economic growth comes from the model itself. Some of them consider that in order to achieve sustained economic growth, the overall production function of the economic system must get rid of the decreas- 
ing of marginal output. Romer (1986) considers that the employees in the production process exist the learning by doing effect. It means that employees will gradually master the required skills as they work and keep their working experience. This will improve the productivity of employees, increase corporate profits and drive economic growth. Lucas (1988) believes that enterprise employees will accumulate human capital outside of work, including learning, further education, training, sports and leisure activities. The accumulation of human capital can improve the output level of the enterprise and promote the long run economic growth rate.

Romer (1986) and Lucas (1988) respectively believe that learning by doing and human capital have positive effects on economic growth, but in fact, the learning by doing effect and human capital accumulation exist at the same time. Therefore, our paper attempts to establish a theoretical model of endogenous economic growth by combining the learning by doing effect and human capital accumulation to explore the long run economic growth rate of the economic system. Finally, our results will be compared and analyzed with Lucas (1988).

\section{Literature Review}

Romer (1986) considers that the learning by doing effect can not only improve the work efficiency of individual employees, but also the accumulated work experience will become the common capital of the enterprise and the overall economy system. These common capitals have spillover effect, which will jointly improve the production efficiency of other employees, increase the marginal productivity of labor, and further make the long-term economic growth rate shows stable positive growth. The research result shows that when the sum of real capital share and spillover effect of learning by doing is greater than or equal to 1 , the long run economic growth rate of the economic system appears positive growth. When the sum of real capital share and spillover effect of learning by doing is less than 1, the result will back to Solow (1956). It means that there will be a steady-state equilibrium in the economic system, that is, the long run economic growth rate is 0 . It shows that if learning by doing spillover effect is not obvious, the long run economic growth rate will not show positive growth.

King and Robson (1989) found that when an economic department makes a new investment plan, it will produce a demonstration effect and a contagion effect of learning by watching for other economic departments. It will improve the productivity, production efficiency and economic growth rate of economic system. It means that the spillover effect of learning by doing does exist and is significant enough to promote the long run economic growth rate always stable and positive growth.

Lucas (1988) believes that enterprise employees will accumulate human capital outside of work, there is constant return to scale characteristic between investment time and human capital, and human capital has spillover effect. The research result shows that when there is no spillover effect of human capital, the 
long run economic growth rate is still positive. If considering the spillover effect of human capital, the long run economic growth rate can be further improved. Human capital not only has internal effects on the production of individual enterprises, but also has external effects on the production of the overall economic system. Therefore, in the short term, it has the level effect of changing the output level. In the long term, it has the growth effect of increasing the economic growth rate.

Since Lucas (1988), many economists have focused on the issue of human capital. Becker, Murphy and Tamura (1990) found that there is an interactive relationship between human capital and fertility. The accumulation of human capital determines the path from low-income equilibrium to high-income equilibrium. It shows that human capital plays an extremely important role in the process of national economic development.

Under the open economy, many studies have found that countries can introduce innovative technology and human capital through international trade, which can enable countries participating in trade to quickly improve the output level, especially countries with relatively backward economic development, which is called catch up effect. This means that the technology gap and knowledge gap between countries can quickly catch up through international trade, narrow the gap, and accelerate a country's economic growth. It also means that human capital makes a more significant contribution to economic growth. Grossman and Helpman $(1990,1991)$ and Shaw (1992) considered that international trade will contribute to the accumulation of a country's knowledge stock and the improvement of its technical level. Romer (1990) and Rebelo (1991) also believe that human capital belongs to the production function of reproducible factors and has the characteristics of non-decreasing returns to scale, so it can accelerate capital accumulation and promote economic growth.

\section{Theoretical Model Setting and Analysis}

Our paper is based on Lucas (1988) human capital model and combined Romer (1986) the concept of learning by doing. We consider that both human capital and social average capital accumulated by learning by doing have spillover effects. According to these settings to establish an endogenous growth model under a closed economic system, we assume that the members of the system are only composed of representative household with infinitely lived and perfect foresight. There is no government and money in the economic system.

The household is postulated to choose his private level of consumption, $c_{t}$, real capital, $k_{t}$, human capital, $h_{t}$, and labor time, $l_{t}$ so as to maximize the discounted sum of future instantaneous utilities:

$$
U=\int_{0}^{\infty} \frac{c_{t}^{1-\sigma}-1}{1-\sigma} \cdot e^{-\rho t} d t ; \sigma>0, \rho>0
$$

In Equation (1), where $\rho$ is the constant rate of time preference, and $\sigma$ is the inverse of the elasticity of intertemporal substitution which measures the 
curvature of the utility function. The instantaneous utility function is equivalent to a logarithmic utility function, $\ln c_{t}$, if $\sigma=1$.

Following Romer (1986) and Lucas (1988), the domestic output $y_{t}$ is produced by real capital $k_{t}$ and efficiency labor $l_{t} h_{t}$, and we consider that both human capital and social average capital accumulated by learning by doing have spillover effects. The production function can be described as follow:

$$
y_{t}=A k_{t}^{\alpha}\left(l_{t} h_{t}\right)^{1-\alpha} h_{a}^{\gamma} \bar{k}^{n} ; 0<\alpha<1, \gamma>0, n>0
$$

In Equation (2), where $A$ is the parameter of production technology, $\alpha$ is the real capital share, $1-\alpha$ is the efficiency labor share, $h_{a}$ is the human capital accumulation of economic system, $h_{a}^{\gamma}$ is the spillover effect of human capital, $\bar{k}$ is the average social capital accumulation by learning by doing, and $\bar{k}^{n}$ is the spillover effect of average social capital.

In terms of the accumulation of real capital, we assume that there is no labor growth and depreciation, so it can be described as follow:

$$
\dot{k}_{t}=A k_{t}^{\alpha}\left(l_{t} h_{t}\right)^{1-\alpha} h_{a}^{\gamma} \bar{k}^{n}-c_{t}
$$

Following Lucas (1988), the time invested is constant return to scale with the accumulation of average human capital per capita, so it can be described as follow:

$$
\dot{h}_{t}=\delta\left(1-l_{t}\right) h_{t}
$$

In Equation (4), where $\left(1-l_{t}\right)$ is the time for representative household to invest in human capital, and $\delta$ is the parameter of human capital productivity, it means that the growth rate of human capital is a fixed proportion of invest time.

According to above setting, we can be described the optimal problem of economic system as follow:

$$
\begin{gathered}
\operatorname{Max} U=\int_{0}^{\infty} \frac{c_{t}^{1-\sigma}-1}{1-\sigma} \cdot e^{-\rho t} d t \\
\text { s.t. } \dot{k}_{t}=A k_{t}^{\alpha}\left(l_{t} h_{t}\right)^{1-\alpha} h_{a}^{\gamma} \bar{k}^{n}-c_{t} \\
\dot{h}_{t}=\delta\left(1-l_{t}\right) h_{t}
\end{gathered}
$$

The current-value Hamiltonian for the agent's optimization is given by:

$$
H=\frac{c_{t}^{1-\sigma}-1}{1-\sigma}+\lambda_{t}\left[A k_{t}^{\alpha}\left(l_{t} h_{t}\right)^{1-\alpha} h_{a}^{\gamma} \bar{k}^{n}-c_{t}\right]+\mu_{t}\left[\delta\left(1-l_{t}\right) h_{t}\right]
$$

In Equation (8), $\lambda_{t}$ and $\mu_{t}$ represent the shadow prices of two production factors: real capital and human capital. According this equation we can solve the first order condition of the optimal solution as follow:

$$
\begin{gathered}
c_{t}^{-\sigma}=\lambda_{t} \\
\lambda_{t}=\left[(1-\alpha) A k_{t}^{\alpha} l_{t}^{-\alpha} h_{t}^{1-\alpha} h_{a}^{\gamma} \bar{k}^{n}\right]-\mu_{t} \delta h_{t}=0 \\
\lambda_{t}\left[\alpha A k^{\alpha-1}\left(l_{t} h_{t}\right)^{1-\alpha} h_{a}^{\gamma} \bar{k}^{n}\right]=-\dot{\lambda}_{t}+\rho \lambda_{t}
\end{gathered}
$$




$$
\lambda_{t}(1-\alpha) A k_{t}^{\alpha} l_{t}^{1-\alpha} h_{t}^{-\alpha} h_{a}^{\gamma} \bar{k}^{n}+\mu_{t} \delta\left(1-l_{t}\right)=-\dot{\mu}_{t}+\rho \mu_{t}
$$

Since our model includes both real capital and human capital, it must be satisfying the following transversality condition. The purpose is to require that real capital and human capital cannot accumulate indefinitely to ensure that the economic system can converge to a stable state.

$$
\lim _{n \rightarrow \infty} \lambda_{t} k_{t} e^{-\rho t}=\lim _{n \rightarrow \infty} \mu_{t} h_{t} e^{-\rho t}=0
$$

Under the long run equilibrium of macroeconomic system, the human capital accumulation by individuals and the human capital accumulation of economic system are regarded as the same factors of production; the real capital and the average social capital accumulation by learning by doing are also regarded as the same factors of production. It means that $h_{t}=h_{a}$ and $k_{t}=\bar{k}$. Then, by combining the constraint of optimal problem and the first order condition, the following macroeconomic equilibrium conditions can be obtained:

$$
\begin{gathered}
g_{c}=\frac{1}{\sigma}\left(\alpha A k_{t}^{\alpha+n-1} l_{t}^{1-\alpha} h_{t}^{1+\gamma-\alpha}-\rho\right) \\
g_{k}=A k_{t}^{\alpha+n-1} l_{t}^{1-\alpha} h_{t}^{1+\gamma-\alpha}-\frac{c_{t}}{k_{t}} \\
g_{h}=\delta\left(1-l_{t}\right) \\
g_{l}=\left(\frac{\alpha+n}{\alpha}\right) g_{k}-\left(\frac{\alpha-\gamma}{\alpha}\right) g_{h}+\frac{1}{\alpha}\left(\delta-\alpha A k_{t}^{\alpha+n-1} l_{t}^{1-\alpha} h_{t}^{1+\gamma-\alpha}\right)
\end{gathered}
$$

According to the macroeconomic equilibrium conditions, at optimal balance growth path, the long run growth rate of labor time is 0 , and the relationship between long run growth rate of consumption, real capital and human capital can be described as follows:

$$
g_{c}=g_{k}=\left(\frac{1+\gamma-\alpha}{1-\alpha-n}\right) g_{h}=\left(\frac{1+\gamma-\alpha}{1-\alpha-n}\right) \delta\left(1-l_{t}\right)
$$

According to equation (18), when the spillover effect of human capital and learning by doing do not exist $(\gamma=0, n=0)$, the long run economic growth rate is equal to the growth rate of human capital. When we only consider the spillover of human capital $(\gamma>0, n=0)$, the long run economic growth rate will be greater than the growth rate of human capital, and the greater the spillover effect, the greater the gap between the two. If we both consider the spillover effect of human capital and learning by doing $(\gamma>0, n>0)$, it will further promote and improve the economic growth rate of the system.

We substitute Equation (18) into macroeconomic equilibrium conditions, the growth rate of human capital and the economic growth rate can be obtained:

$$
\begin{gathered}
g_{h}=\left[\frac{1-\alpha-n}{\sigma(1+\gamma-\alpha)-(n+\gamma)}\right](\delta-\rho) \\
g_{c}=g_{k}=\left[\frac{1+\gamma-\alpha}{\sigma(1+\gamma-\alpha)-(n+\gamma)}\right](\delta-\rho)
\end{gathered}
$$


Then, we compare the research result of this paper with Lucas (1988) which the model exists the spillover effect of human capital, and analysis the difference between two of them. The growth rate of human capital in Lucas (1988):

$$
g_{h}^{L}=\left[\frac{1-\alpha}{\sigma(1+\gamma-\alpha)-\gamma}\right](\delta-\rho)
$$

Subtract Equation (21) from Equation (19): $g_{h}-g_{h}^{L}=n(1+\gamma-\alpha)(1-\sigma)>0$. The result shows that when we consider the spillover effect of learning by doing, if the inverse of the elasticity of intertemporal substitution is not equal to 1 $(\sigma \neq 1)$, the growth rate of human capital in our paper will greater than that of Lucas (1988). If the inverse of the elasticity of intertemporal substitution is equal to $1(\sigma=1)$, the growth rate of human capital in our paper is the same as that in Lucas (1988), it is $(\delta-\rho)$. Therefore, we can get the following proposition:

Proposition 1: considering the spillover effect of human capital and learning by doing at the same time, when the inverse of the elasticity of intertemporal substitution is not equal to $1 \quad(\sigma \neq 1)$, the growth rate of human capital will be higher than that considering only the spillover effect of human capital. When the inverse of the elasticity of intertemporal substitution is equal to $1(\sigma=1)$, the growth rate of human capital will show a fixed growth.

The long run economic growth rate in Lucas (1988):

$$
g_{c}^{L}=g_{k}^{L}=\left[\frac{1+\gamma-\alpha}{\sigma(1+\gamma-\alpha)-\gamma}\right](\delta-\rho)
$$

Compare Equation (22) with Equation (20), it is obvious that the result obtained in our paper is higher than that in Lucas (1988). It means that the spillover effect of learning by doing can indeed further drive the long run economic growth rate, and this result is not affected by the inverse of the elasticity of intertemporal substitution. Therefore, we can get the following proposition:

Proposition 2: considering the spillover effect of human capital and learning by doing at the same time, no matter what the inverse of the elasticity of intertemporal substitution, the long run economic growth rate will be higher than that considering only the spillover effect of human capital. It shows that the spillover effect of learning by doing can further drive the long run economic growth rate.

\section{Conclusion}

According to Romer (1986) and Lucas (1988), whether workers improve work efficiency through learning by doing at work or accumulate their own human capital after work, they can improve enterprise profits and drive economic growth, which also shows that learning by doing and human capital are an important driving force for the continuous improvement of long run economic growth rate.

However, in fact, the learning by doing effect and human capital accumulation is not independent of each other but exist at the same time. Therefore, our 
paper attempts to establish a theoretical model of endogenous economic growth by combining the learning by doing effect and human capital accumulation to explore the long run economic growth rate of the economic system.

Our research has found that when we both consider the spillover effect of human capital and learning by doing, if the inverse of the elasticity of intertemporal substitution is not equal to $1 \quad(\sigma \neq 1)$, the growth rate of human capital can be further improved compared with Lucas (1988). If the inverse of the elasticity of intertemporal substitution is equal to $1(\sigma=1)$, the growth rate of human capital will show a fixed growth.

In terms of long run economic growth rate, when we both consider the spillover effect of human capital and learning by doing, no matter what the inverse of the elasticity of intertemporal substitution, the long run economic growth rate will be higher than that considering only the spillover effect of human capital. It shows that learning by doing and human capital has a positive effect on the economic growth rate. Even if the growth rate of human capital shows a fixed growth, the learning by doing effect can also further drive the long run economic growth rate of the system.

\section{Conflicts of Interest}

The authors declare no conflicts of interest regarding the publication of this paper.

\section{References}

Becker, G. S., Murphy, K. M., \& Tamura, R. (1990). Human Capital, Fertility, and Economic Growth. Journal of Political Economy, 98, S12-S37.

https://doi.org/10.3386/w3414

Grossman, G., \& Helpman, E. (1990). Comparative Advantage and Long Run Growth. American Economic Review, 80, 769-875.

Grossman, G., \& Helpman, E. (1991). Innovation and Growth in the Global Economy. MIT Press.

King, R. G., \& Robson, R. (1989). Endogenous Growth and the Role of History. LSE Financial Markets Group Discussion Paper. https://doi.org/10.3386/w3151

Lucas, R. E. (1988). On the Mechanics of Economic Development. Journal of Monetary Economics, 21, 3-42. https://doi.org/10.1016/0304-3932(88)90168-7

Rebelo, S. (1991). Long Run Policy Analysis and Long Run Growth. Journal of Political Economy, 99, 500-521. https://doi.org/10.1086/261764

Romer, P. M. (1986). Increasing Return and Long Run Growth. Journal of Political Economy, 94, 1002-1037. https://doi.org/10.1086/261420

Romer, P. M. (1990). Endogenous Technological Change. Journal of Political Economy, 98, 71-102. https://doi.org/10.1086/261725

Shaw, G. K. (1992). Policy Implications of Endogenous Growth Theory. Economic Journal, 102, 611-621. https://doi.org/10.2307/2234298

Solow, R. (1956). A Contribution to the Theory of Economic Growth. Quarterly Journal of Economics, 70, 65-94. https://doi.org/10.2307/1884513 